\title{
NO EVIDENCE OF BODY SIZE EFFECTS ON THE REPRODUCTIVE BEHAVIOUR OF A NON-TERRITORIAL DAMSELFLY CHALCOLESTES VIRIDIS
}

\author{
Amin Kahalerras ${ }^{a}$, Nedjwa Boucenna ${ }^{a}$, Zinette Bensakhri ${ }^{c^{*}}$, Mouhamed Boukhamza ${ }^{a}$ and Moussa Houhamdi ${ }^{b}$ \\ aDepartment of Biology, Faculty of Biological and Agricultural Sciences, University of Tizi Ouzou, Tizi Ouzou 15000, Algeria;

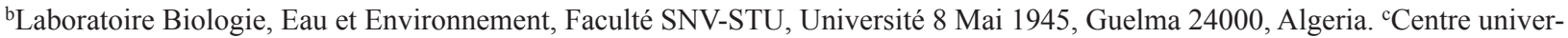 \\ sitaire Abdelhafid Boussouf-Mila, Institut des Sciences et de la Téchnologie, Departement des Sciences de la Nature et de la Vie, \\ Algeria \\ *Corresponding author. Email: zinette_29@yahoo.fr
}

Article history Received: 25 February 2019; accepted 27 January 2020

\section{Keywords:}

Damselfly; odonates;

Lestidae; reproduction;

North Africa; Algeria

\begin{abstract}
Body size has important effects on reproductive behaviour and fitness of species. Although body size is usually advantageous for territorial species, its direct implication in determining the behaviour of non-territorial species is still not well understood. Here we investigate the reproductive behaviour of a non-territorial damselfly Chalcolestes viridis in northeast Algeria and assess the effects of body size on different behavioural and ecological components. The diurnal pattern of abundance depended on temperature and hour of the day, showing a peak within temperatures ranging between $23^{\circ}$ and $26^{\circ} \mathrm{C}$. Copulation and oviposition duration were not correlated to body size and did not change across the season. In addition, the species oviposited eggs in wooden substrates that were 150-200 cm above the water surface, and this vertical stratification was negatively correlated to branch diameter and water depth, positively correlated with water width and velocity, but was not correlated with body size and season. Our study suggests that body size might not be very relevant in shaping certain aspects of reproductive behaviour and habitat selection in non-territorial damselflies, but could influence other fitness components.
\end{abstract}

\section{INTRODUCTION}

Insect body size is an important life history trait that has several physiological and evolutionary implications (Stearns 1992; Blanckenhorn 2000). Larger body size may confer benefits to both males and females. For instance, in territorial species, males win more contests for resource acquisition which increases their reproductive success (Thornhill and Alcock 1983), whereas larger females can produce more eggs and have more offspring (Andersson 1994; Rodriguero et al. 2002; Miller and Svensson 2014). Although the advantages of a larger body size in territorial species have been well documented, the implication of body size in physiological and behavioural characters in non-territorial species remains an open hot topic in evolutionary biology.

Odonate adults are good model organisms to assess the reproductive behaviour and body size effects because they are conspicuous, widespread, easily marked, mostly confined to freshwater ecosystems, and their body size does not change with age during the adult stage (CorderoRivera and Stoks 2008). Many species are territorial, non-territorial, or show mixed strategies (Fincke 1985; Banks and Thompson 1987; Corbet 1999; Koskimäki et al. 2009). In many non-territorial species, males use a scramble competition tactic for mates to ensure egg fertilization and oviposition by staying attached to the female after copulation (Stoks et al. 1997; Corbet 1999). This is the case for Chalcolestes viridis, a non-territorial lestid damselfly which is widespread in Europe and northern Maghreb. North African Lestidae are known to have different reproductive strategies that involve variation in reproductive season along clinal gradients in habitat (Amari et al. 2019). The species lives in permanent slow-flowing water which is bordered with bushes and trees. Egg laying takes place in wooden substrates near the water, so that after hatching larvae fall into the water and start their larval life. This mode of oviposition suggests that females select oviposition localities that best ensure the survival of the eggs and larvae after hatching. Hence, microhabitat selection during oviposition might be a complex decision depending on the interplay between characteristics of both the terrestrial habitat (related to the wooden substrate) and aquatic system (related to the physical features of the water) (Waage 1987; Rehfeldt 1990; Martens 1993; Martens 2001; Allen et al. 2010). Although the life cycle and behaviour of the species has been studied (Dreyer 1978; Cordero 1988; Ferreras-Romero 1988; AgüeroPelegrin et al. 1999), few studies have looked at body size and morphometric effects on the different aspects of its reproductive behaviour (De Block and Stoks 2007). 
In this study, we present an investigation carried out in the North African hotspot, the Seybouse River in northeast Algeria (Khelifa 2011; Khelifa et al. 2016b), on a natural population of Chalcolestes viridis. The aim of the study was to characterize: (1) the diurnal pattern of abundance by looking at hourly distribution of adults (males, females and reproductive pairs), (2) body size and sexual size dimorphism (SSD), (3) reproductive behaviour, focusing on copulation and oviposition duration by surveying individually marked adults, and (4) microhabitat selection during oviposition by using a multivariate approach to determine the main environmental factors determining habitat choice. We also tested for potential correlations between temperature, body size and different aspects of reproductive behaviour.

\section{MATERIALS AND METHODS}

\section{Study species}

Chalcolestes viridis is a medium-sized damselfly confined to Europe and northern Maghreb. The species used to be assigned to the genus Lestes, but due to some larval characteristics such as a broad instead of a greatly narrowed (spoon-shaped) prementum, it was moved along with C. parvidens to the genus Chalcolestes (Gyulavári et al. 2011). The species often reproduces in permanent slow-flowing water bordered with trees or bushes where eggs are deposited in soft wood (Dijkstra and Lewington 2006). The species is abundant across its range and is currently listed as, "least concern", in the IUCN Red list (Boudot et al. 2009).

\section{Study site}

Our investigation was conducted at the Old Bridge canal, which is $8 \mathrm{~km}$ upstream on the Seybouse River, and $5 \mathrm{~km}$ west of Guelma city $\left(36^{\circ} 28.3^{\prime} \mathrm{N}, 7^{\circ} 22.3^{\prime} \mathrm{E}\right)$ (Figure 1). The watercourse is about $0.5 \mathrm{~km}$ long with a depth of $7 \mathrm{~cm}$ and width of $120 \mathrm{~cm}$ (Khelifa et al. 2013). The study on Chalcolestes viridis was carried out upstream of the canal, within a transect of $250 \mathrm{~m}$ where the banks are dominated with bushes of Oleander (Nerium oleander) and a few olive trees (Olea Europea). There were sparse patches of cattail (Typha angustifolia) and knotgrass (Paspalum distichum). At this part of the canal the odonatofauna was not diverse and it consisted mainly of the green emerald (Chalcolestes viridis), copper demoiselle (Calopteryx haemorrhoidalis), barbary featherleg (Platycnemis subdilatata) and epaulet skimmer (Orthetrum chrysostigma).

\section{Adult sampling and thermal preferences}

An hourly pattern of abundance of individuals of Chalcolestes viridis was investigated by daily walking across the study transect from 09:00 to 17:00 and recording the number of males, single females and reproductive pairs. We assessed the thermal preferences of reproduction by combining abundance with temperature data. We used daily average air temperature from a meteorological station which is $7 \mathrm{~km}$ distant from the study area.

\section{Copulation and oviposition duration}

To assess the reproductive behaviour of the species, we surveyed from 3 September to 10 October 2012 daily

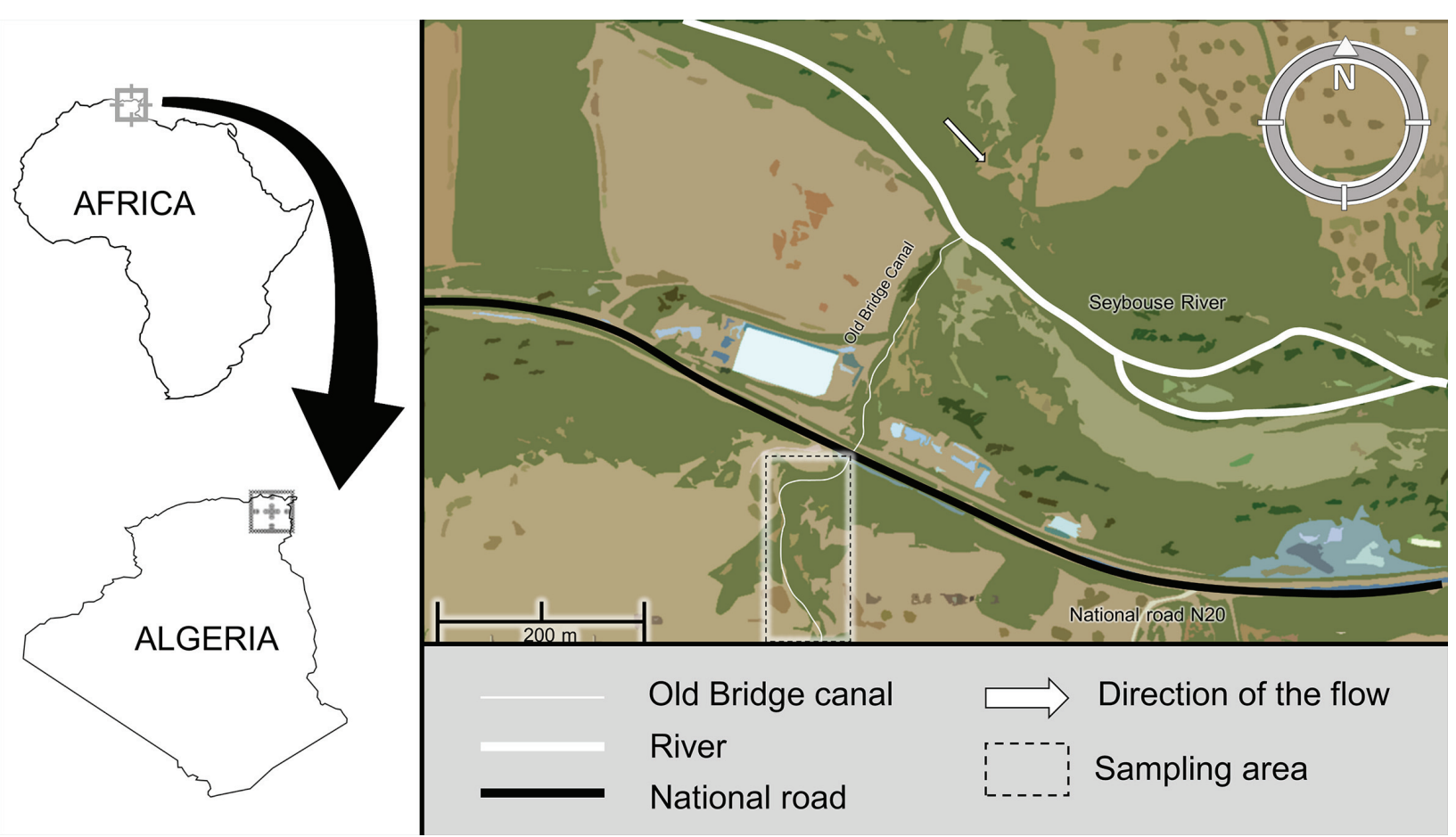

Figure 1. Study area of the natural population of Chalcolestes viridis in northeast Algeria. 
by marking individuals with a permanent marker on the left hind wing. Individual alphanumeric codes were assigned for each mature imago. This marking enabled us to precisely estimate the duration of copulation and oviposition of each breeding pair. When captured, the body length and posterior wing length were measured with a digital caliper to the nearest $0.01 \mathrm{~mm}$. The potential effect of body size in determining oviposition site selection was also tested. For each sampling occasion, we recorded the duration of copulation during the reproductive period of the day (see results), i.e. from the formation of wheel position (intromission) until the removal of the male penis from the female genital parts. We also estimated the duration of oviposition, i.e. from the first until the last egg laid and the separation of the breeding pair. For both copulation and oviposition duration, we investigated their potential relationship with body size.

\section{Habitat selection for oviposition}

Chalcolestes viridis is probably the only lotic damselfly in North Africa that carries out oviposition exclusively in wooden plants. The choice of oviposition site depends on environmental variables related not only to the plant but also to the water. To understand oviposition site selection, we recorded (1) the plant used for oviposition and estimated the oviposition height to the nearest $\mathrm{cm}$ with a decametre (from the position where the eggs were laid to the water surface), (2) the branch's diameter where the eggs were laid estimated with a caliper to the nearest $0.01 \mathrm{~cm},(3)$ water depth in the middle of the water course to the nearest $\mathrm{cm}$ with a gridded stick, (4) water velocity by calculating the time in seconds spent by a floating object within $2 \mathrm{~m}$. When the position of the ovipositing pair changes, we take into account the position where most oviposition duration was spent.

\section{Statistical analyses}

Statistical analyses were all performed with R 3.2.2 (R Development Core Team 2019). Due to a strong correlation between body and posterior wing length (Spearman's rank correlation: $r=0.65, p<0.0001$ ), we used body length as a measure of body size hereafter. To analyse the relationship between the abundance of the reproductive pairs and hours of the day and air temperature, we carried out a generalized quasipoisson model with abundance as a response variable and temperature and hour (linear and quadratic term) of the day as explanatory variables. A seasonal pattern of abundance was analyzed with a Poisson mixed effects model using individual groups (males, females and reproductive pairs) and Julian date as an explanatory variable and hour as a random effect. The seasonal pattern of copulation and oviposition duration (response variable) were tested with linear models by using Julian date as an explanatory variable. The potential relationship between copulation and oviposition duration was tested with Spearman's rank correlation test. The relationships of body size (body length), copulation and oviposition duration with oviposition height were tested with linear models. Values are mean \pm SD.

\section{RESULTS}

\section{Climatic conditions}

During the study period, the average temperature was $24.78 \pm 2.58^{\circ} \mathrm{C}$, ranging from an average minimum and maximum of $16.68 \pm 3.04^{\circ} \mathrm{C}$ and $30.83 \pm 3.76^{\circ} \mathrm{C}$, respectively (Figure 2). There was a weak but a significant negative temporal pattern of average temperature $(r=$ $-0.03, \mathrm{SE}=0.01, \mathrm{R}^{2}=0.07 ; p=0.03$ ). Out of the 58 days of our survey, rainfall was recorded in only five days with an average of $1.47 \pm 6.07 \mathrm{~mm}$, whereas wind speed had an average of $5.18+3.17 \mathrm{~km} \cdot \mathrm{h}^{-1}$, which, according to Beaufort scale, is ranked as a light breeze. This means that climatic conditions during our survey were mostly favourable for behavioural observations.

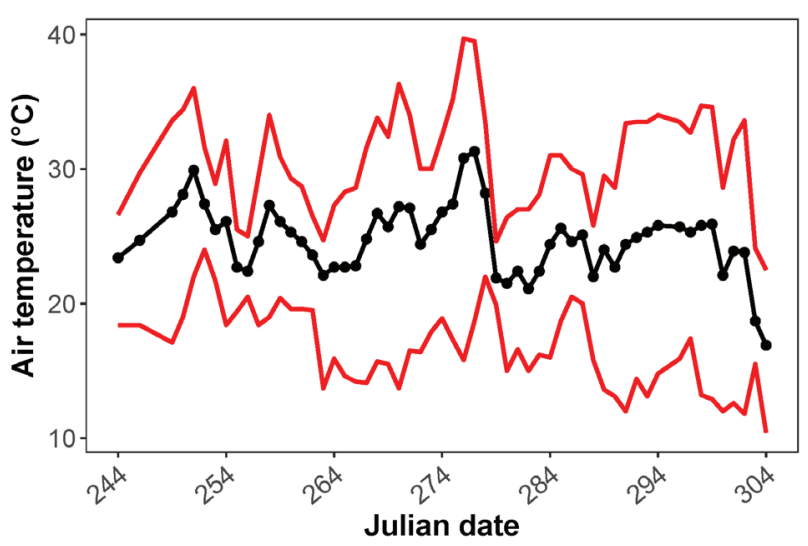

Figure 2. Thermal regime in the study area during the reproductive season of Chalcolestes viridis. Black line is the average air temperature and lower and upper red lines are minimum and maximum temperature, respectively.

\section{Diurnal behaviour and temperature}

Single males and females had different diel activity patterns (Figure 3). While the number of males did not show any diurnal trend, meaning that their abundance remained relatively constant from 9:00 to 17:00 (12.79 $\pm 6.93, \mathrm{~N}=243$ ), the number of single females declined from 9:00 $(12.37 \pm 13.43, \mathrm{~N}=27)$ to $13: 00-14: 00(3.05$ $\pm 2.63, \mathrm{~N}=54)$ and then increased in later hours until $17: 00(7.33 \pm 6.43, N=27)$. Breeding couples started to appear at 10:00 $(0.12 \pm 0.43, \mathrm{~N}=27)$, peaked at 14:00 $(2.88 \pm 3.97, \mathrm{~N}=27)$, then gradually declined until 17:00 $(0.81 \pm 1.76, \mathrm{~N}=27)$ (Figure 3$)$. In addition to the hour of the day, the number of breeding couples was affected 

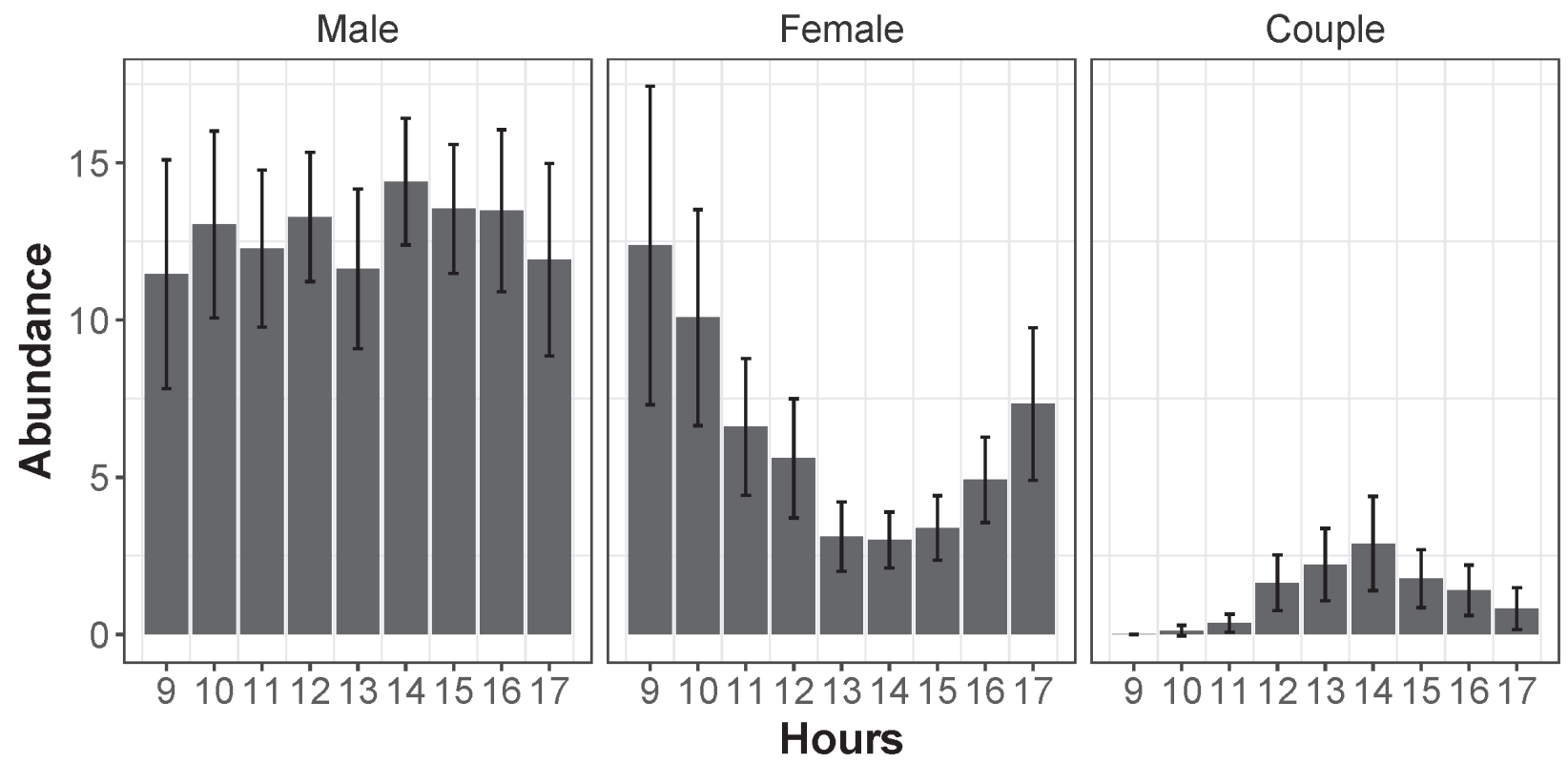

Figure 3. Diel pattern of abundance of male, female and reproductive pairs (couples) of Chalcolestes viridis in the study site. Error bars are $95 \%$ confidence intervals.

Table 1. Summary results of the generalized quasipoisson model assessing the pattern of the number of breeding couples across hours of the day and temperature (T).

\begin{tabular}{|l|l|l|l|l|}
\hline & Estimate & Std. Error & \multicolumn{1}{c|}{$t$ value } & \multicolumn{1}{c|}{$p$ value } \\
\hline (Intercept) & -58.565 & 14.350 & -4.081 & $<0.0001$ \\
\hline Hour & 4.984 & 0.852 & 5.848 & $<0.0001$ \\
\hline Hour $^{2}$ & -0.176 & 0.030 & -5.753 & $<0.0001$ \\
\hline $\mathrm{T}$ & 2.017 & 1.008 & 2.002 & 0.046 \\
\hline $\mathrm{T}^{2}$ & -0.041 & 0.019 & -2.099 & 0.037 \\
\hline
\end{tabular}

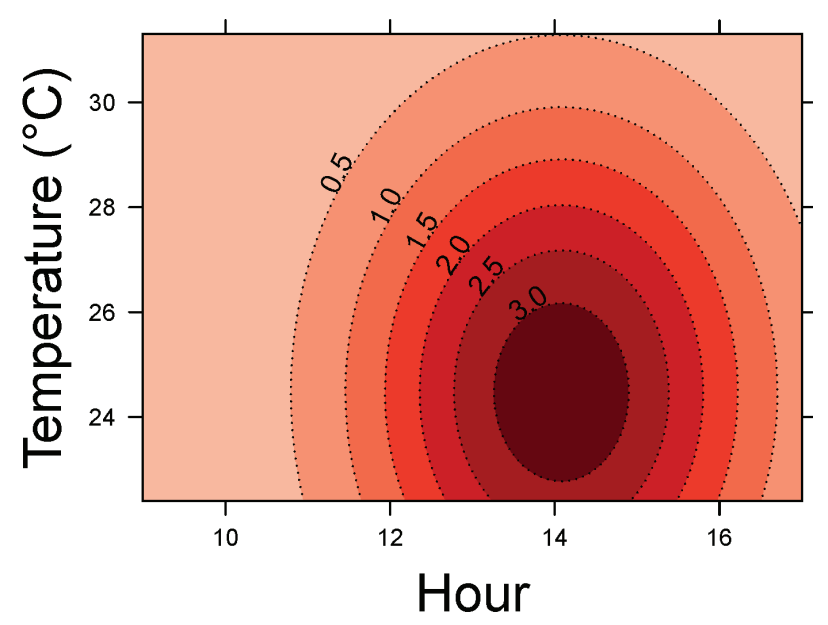

Figure 4. Predicted number of reproductive pairs of Chalcolestes viridis across hours of the day and air temperature.

by temperature (both linear and quadratic effects) such that there was an optimum between 23 and $26{ }^{\circ} \mathrm{C}$ where the maximum numbers were recorded, but temperatures beyond the optimum tended to reduce the number of pairs (Table 1, Figure 4). There was a seasonal pattern
Table 2. Summary results of the Poisson mixed effects model assessing the seasonal pattern of abundance of Chalcolestes viridis males, females and breeding couples. Group is either male, female or reproductive couple. The intercept is the baseline group 'reproductive couple'.

\begin{tabular}{|c|c|c|c|c|}
\hline \multicolumn{5}{|c|}{ Random effects } \\
\hline Groups & Name & Variance & Std. Dev. & \\
\hline Hour & Intercept & 0.007 & 0.081 & \\
\hline & & $\mathrm{N}=682$ & Hour $=9$ & \\
\hline \multicolumn{5}{|c|}{ Fixed effects } \\
\hline & Estimate & Std. Error & $z$ value & $p$ value \\
\hline Intercept & 0.246 & 0.065 & 3.800 & $<0.0001$ \\
\hline Season & 0.075 & 0.058 & 1.280 & 0.2010 \\
\hline Group [Female] & 1.366 & 0.067 & 20.300 & $<0.0001$ \\
\hline Group [Male] & 2.299 & 0.062 & 37.260 & $<0.0001$ \\
\hline $\begin{array}{l}\text { Season:Group } \\
\text { [Female] }\end{array}$ & -0.761 & 0.068 & -11.170 & $<0.0001$ \\
\hline $\begin{array}{l}\text { Season:Group } \\
\text { [Male] }\end{array}$ & -0.139 & 0.062 & -2.260 & 0.0240 \\
\hline
\end{tabular}

of abundance showing that males and females declined in numbers (but more so for females), but the number of breeding couples did not change across the season (Table 2).

\section{Body size and sexual size dimorphism}

There was a male-biased SSD in body length, but a female-biased SSD in wing length (Figure 5). Body length was longer in males $(42.61 \pm 2.47, \mathrm{~N}=175)$ than in females $(39.84 \pm 1.60, \mathrm{~N}=147)(\mathrm{W}=4147$, $p<0.0001)$, but wing length was larger in females $(24.94$ $\pm 0.78, \mathrm{~N}=147)$ than in males $(23.56 \pm 1.08, \mathrm{~N}=175)$ $(\mathrm{W}=22140, p<0.0001)$. 


\section{Copulation and oviposition duration}

Copulation took place near oviposition sites (Figure 6a). The average copulation duration was $12.33 \pm 5.41 \mathrm{~min}$ ( $\mathrm{N}=168,95 \%$ CI: $11.51-13.15 \mathrm{~min}$ ). Copulation duration did not significantly change across the reproductive season $(r=0.03, \mathrm{SE}=0.04, p=0.34$, Figure 7a). Copulation duration was neither correlated with the body length of males $\left(r=-0.67, \mathrm{SE}=0.95, \mathrm{R}^{2}=0.02\right.$, $p=0.48)$ nor with that of females $(r=-0.99, \mathrm{SE}=0.79$, $\mathrm{R}^{2}=0.04, p=0.22$, Figure $7 \mathrm{~b}$ ).

Oviposition took place in pairs (Figure 6b). The average oviposition duration was $70.93 \pm 29.16 \min (\mathrm{N}=168$.

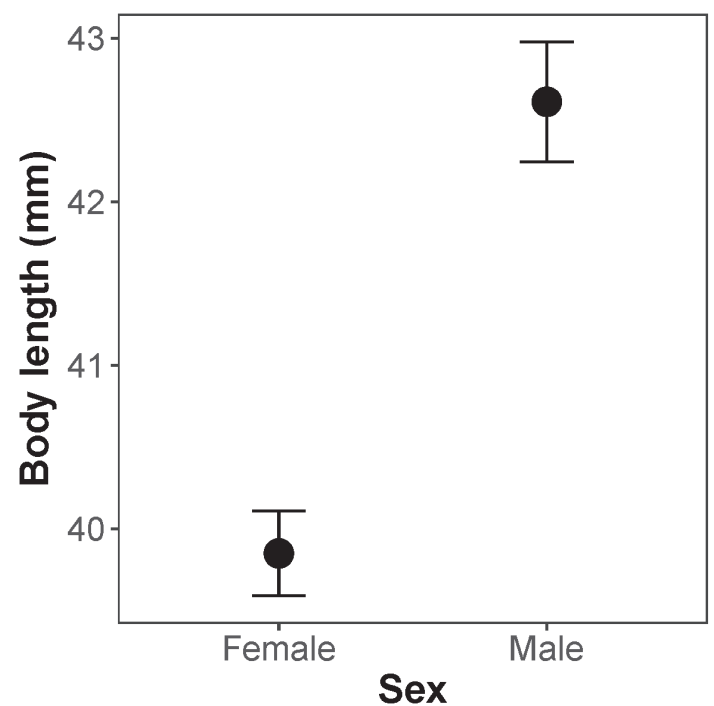

95\% CI: $66.52-75.34 \mathrm{~min})$. The duration of copulation and oviposition were not correlated (Spearman's rank correlation: $r=0.01, p=0.90$ ). Similarly to copulation duration, oviposition duration did not show a seasonal pattern $\left(r=0.09, \mathrm{SE}=0.20, \mathrm{R}^{2}=0.001, p=0.65\right)$ and was not correlated with body length of males $\left(r=-0.88, \mathrm{SE}=2.88, \mathrm{R}^{2}=0.002, p=0.54\right.$, Figure $\left.7 \mathrm{c}\right)$ or females $\left(r=-1.98, \mathrm{SE}=3.56, \mathrm{R}^{2}=0.004, p=0.58\right.$, Figure 7d).

\section{Habitat selection for oviposition}

The species laid eggs quasi-exclusively $(97.8 \%)$ in

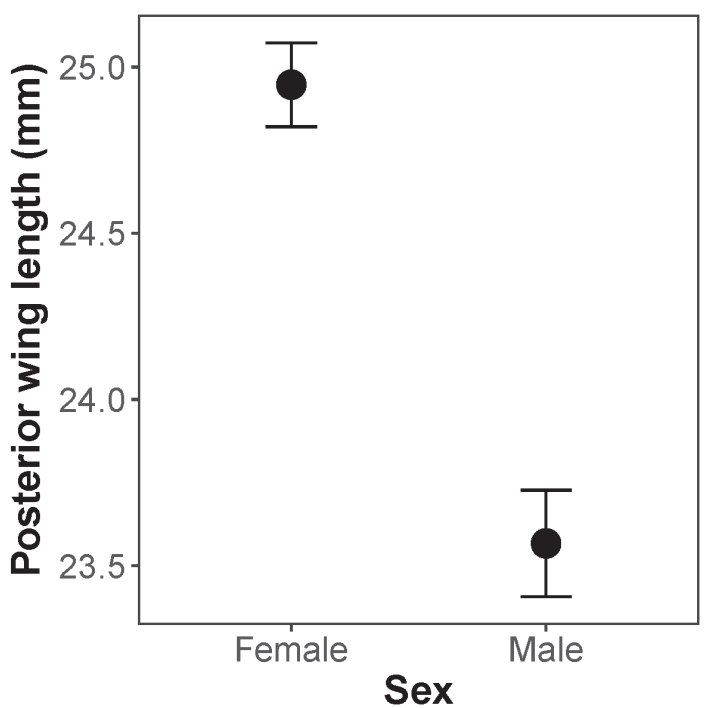

Figure 5. Body and posterior wing lengths of Chalcolestes viridis males and females. Error bars are $95 \%$ confidence intervals.

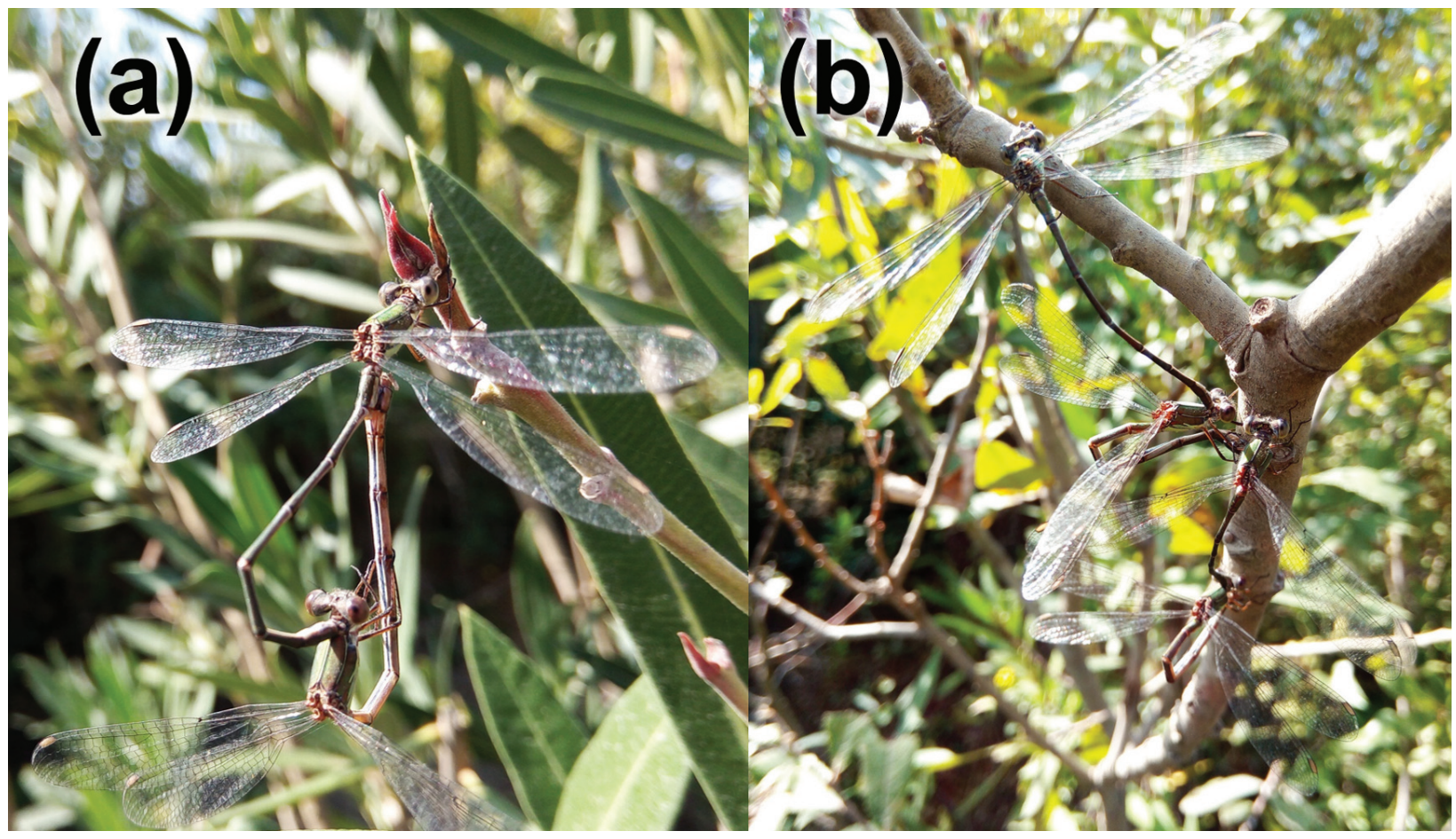

Figure 6. Reproductive pair of Chalcolestes viridis in (a) copulation and (b) oviposition. 

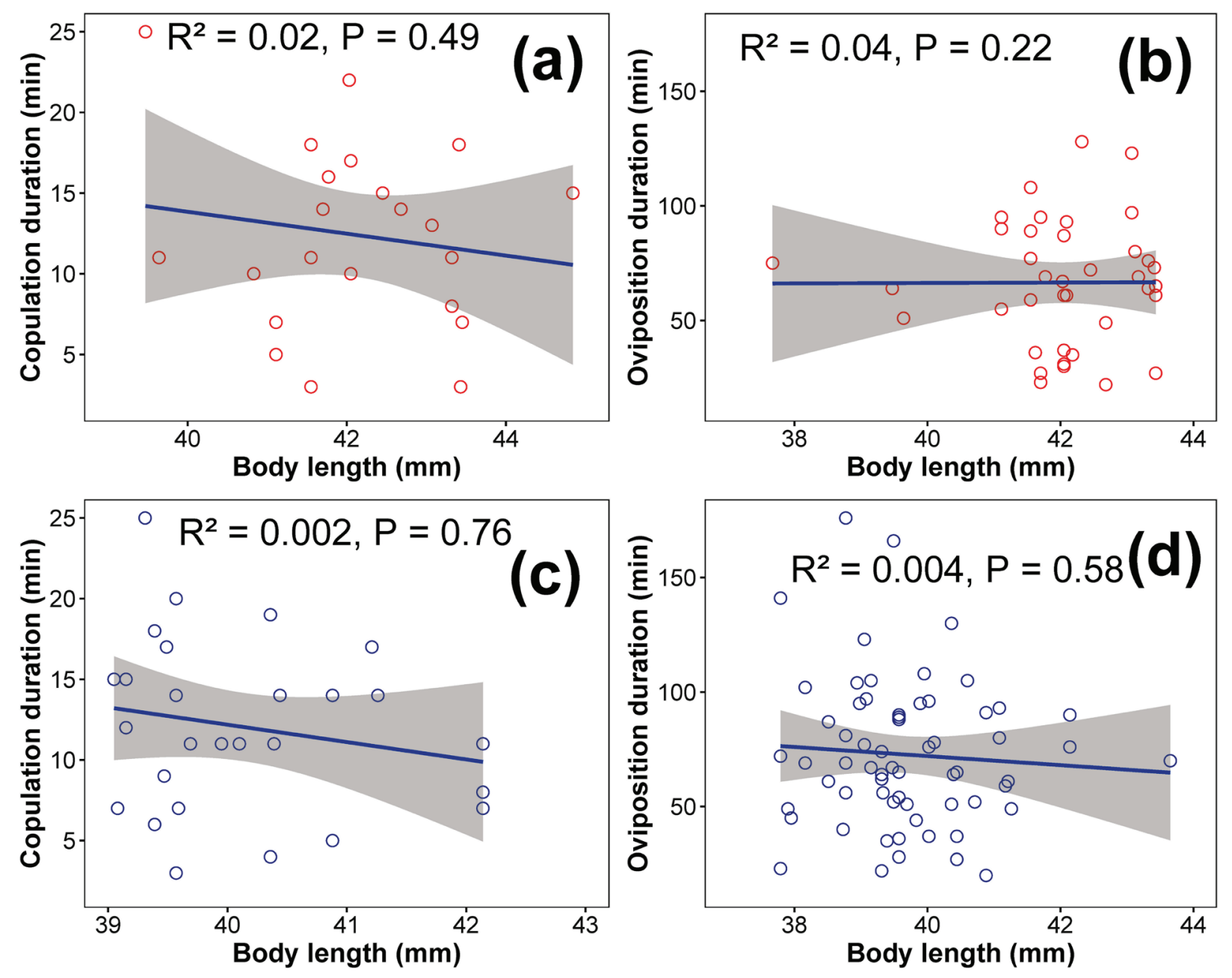

Figure 7. Relationship between body size and copulation and oviposition duration in Chalcolestes viridis; (a) and (b) refer to the effect of body size of male and female on copulation duration, respectively; (c) and (d) refer to the effect of body size of male and females on oviposition duration, respectively.

branches of oleander shrubs (Nerium oleander), but rarely $(2.2 \%)$ in the olive tree (Olea europaea). Of those that used oleander shrubs, $79.7 \%(\mathrm{~N}=106)$ used dry parts of the branch, $14.3 \%(\mathrm{~N}=19)$ used green fresh parts, and $6 \%(\mathrm{~N}=8)$ utilized a mix of dry and fresh parts. Table 3 presents summary statistics of the five environmental variables describing oviposition site selection of the species. The reproductive pairs used intermediate-sized branches for oviposition. This diameter exhibited a constant seasonal pattern (LME: $r=0.012, \mathrm{SE}=0.012, p=0.29)$ with a mean of 4.36 $\pm 1.05 \mathrm{~cm}(\mathrm{~N}=168)$. The height of oviposition had a mean of $167.9 \pm 55.1 \mathrm{~cm}(\mathrm{~N}=168)$, and it showed a marginally non-significant increase across the reproductive season (LME: $r=1.178, \mathrm{SE}=0.615, p=0.06$ ). Pairwise Spearman's correlations between the height of oviposition, diameter of the branch used, water width, depth and velocity showed that the height of oviposition was positively correlated to water width $(p<0.0001)$ and water velocity $(p<0.0001)$, but negatively corre- lated with water depth $(p=0.02)$ and marginally with support diameter $(p=0.05)$. Due to these significant correlations, we used oviposition height as a surrogate of oviposition site selection for testing the effect of body size. Surprisingly, body length of both males (LME: $r=0.622, \mathrm{SE}=0.905, p=0.90)$ and females (LME: $r=-2.836, \mathrm{SE}=7.135, p=0.69)$ did not affect the height of oviposition.

Table 3. Average, SD, and $95 \%$ confidence intervals of five environmental variables related to oviposition site selection of Chalcolestes viridis.

\begin{tabular}{|l|c|c|c|c|c|}
\hline Variables & Mean & SD & LCI & UCI & N \\
\hline $\begin{array}{l}\text { Height of } \\
\text { oviposition }(\mathrm{cm})\end{array}$ & 167.99 & 55.10 & 159.65 & 176.32 & 168 \\
\hline $\begin{array}{l}\text { Diameter of the } \\
\text { support }\left(\mathrm{m}^{-1} \mathrm{~s}^{-1}\right)\end{array}$ & 4.36 & 1.05 & 4.20 & 4.52 & 168 \\
\hline Water depth $(\mathrm{cm})$ & 13.07 & 3.28 & 12.57 & 13.57 & 168 \\
\hline Water velocity $(\mathrm{cm})$ & 0.12 & 0.07 & 0.11 & 0.13 & 168 \\
\hline Water width $(\mathrm{cm})$ & 190.72 & 38.32 & 184.92 & 196.51 & 168 \\
\hline
\end{tabular}




\section{DISCUSSION}

This study investigated the potential effects of body size on the behavioural biology and ecology of a nonterritorial damselfly, hypothesizing that since male-male interference competition is absent, body size should have little effect. We confirmed our hypothesis by showing that body size neither affected copulation, oviposition duration nor oviposition site selection.

We found different diurnal patterns of abundance between single males and females. The former had a relatively stable abundance during the entire day, whereas the later decreased in numbers in the afternoon and increased later in the day. The decline in the number of single females was associated with an increase in the number of reproductive pairs, revealing that pair formation peaks in the middle of the day. A similar diel pattern of occurrence was observed in Erythromma lindenii (Bouiedda et al. 2018). However, the fact that the number of single males was relatively constant across the day and did not decline during the peak of reproductive activity shows that not all mature males find a mate and that although single females were available, breeding pairs were not formed. This suggests that either (1) some males were not effective in searching and encountering females and/or (2) females were choosy and refused to mate with some of the males encountered (Eberhard 1996; Cothran et al. 2012). The number of reproductive pairs was thermally sensitive, showing a peak of activity within $23-26^{\circ} \mathrm{C}$. Knowing that summer temperature often exceeds $35^{\circ} \mathrm{C}$ during most of the afternoon, the thermal sensitivity of the species reflects its local temporal adaptation to autumnal conditions during which temperature is lower than that in the summer.

The copulation duration recorded in our study was similar to that estimated for Spanish populations with 12.16-13.59 min (Córdoba-Aguilar et al. 2003) and 9.1-19.6 min (Uhía and Rivera 2005). Interestingly, copulation duration did not show a significantly different change across the reproductive season although temperature slightly declined later in the season. It might be that copulation duration which consists of different stages like tandem formation and sperm transfer (Uhía and Rivera 2005) is not thermally sensitive in this species. Moreover, body size of males and females did not affect copulation duration, suggesting that there was no link between the body length and tandem duration or sperm transfer. It is not clear whether copulation duration is under the control of males, females or both. First, the theory that prolonged copulation is a mechanism by which males show some kind of copulatory courtship or intrinsic quality (Eberhard 1996) might not be sizedependent in $C$. viridis, or that the intraspecific variation in the complex shape of the aedeagus in males which might influence copulation duration (Takami and Sota
2007) is also not size-dependent. Second, there might be no relationship between body size and bursa and spermathecae size which is known to be quite small for the species (storing 13\% of the sperm) (Uhía and Rivera 2005).

The duration of oviposition was relatively shorter than that reported for a Belgian population in which the average duration was $1.43 \mathrm{~h}$ (De Block and Stoks 2005). This inter-population variation is less likely to be due to morphological variations, but rather to behavioural differences. In fact, since the species is obligatory univoltine, northern populations have a likely smaller body size than southern populations due to seasonal constraints (shorter warm season for development) (Śniegula and Johansson 2010), unlike the typical Bergman's rule where body size increase with latitude (Mousseau 1997). Given the positive relationship between body size and clutch size (Sokolovska et al. 2000) and between clutch size and oviposition duration (Corbet 1999), the shorter oviposition in our study site should not be due to body size differences. Instead, there might be behavioural differences where, depending on the plant species, females spend more time selecting an appropriate location for egg insertion in wooden branches.

The two morphological traits that we measured in C. viridis showed different directions of SSD. Body length was larger in males than in females, which is the case in zygopterans (Serrano-Meneses et al. 2008); however, wing length was larger in females than in males. Although body size did not show a significant effect on the general reproductive behaviour of the species, larger bodies in males may confer a greater ability to mate with females, such as higher energy reserves that increase the endurance of searching for mates (Anholt 1991; Stoks 1999). This may explain the evolution of male-biased SSD in body length. Females are known to have cryptic behaviour, that is, come to the water to lay eggs and leave the water to terrestrial habitats (usually farther than males) to forage and produce eggs (Stoks 2001). This spatial segregation between males and females in foraging habitats can be the result of the evolution of larger wings in females.

Egg laying was conducted in pairs, which is typical of Palearctic Lestes species such as L. macrostigma (Matushkina and Lambret 2011), L. sponsa (Robert, 1958), L. barbarous and C. viridis (Grand \& Boudot, 2007), and L. virens (Amari et al. 2019). Oviposition sites determine the survival of eggs, and thus it is crucial to understand the ecology of oviposition of odonate-plant interaction (Khelifa et al. 2016a; Khelifa and Mellal 2017; Mellal et al. 2018). Oviposition took place mostly exclusively in oleander branches. Corbet (1962) pointed out that many damselflies show preference to a particular species of plant to lay eggs. There was intraspecific vari- 
ation in the height of oviposition, but this variation was not explained by body size. This can be explained by the absence of intraspecific competition for space between reproductive pairs of $C$. viridis which can aggregate during oviposition and lay eggs near one another (De Block and Stoks 2005). Furthermore, there was a marginally non-significant seasonal increase in the height of oviposition which suggests that there might be an overuse of lower strata of the oviposition supports, which induced breeding pairs to select higher strata. On the other hand, the diameter of the branches used for oviposition was relatively constant across the reproductive season. The reproductive pairs used intermediate-sized branches of oleander to lay eggs, and due to the fact that this choice was not affected by seasonally changing environmental factors such as temperature, the diameter of the branches selected should be the one that offers optimal conditions for the development of eggs (Lutz and Pittman 1968). Last but not least, the positive relationship between water width and vertical stratification suggests that larger water beds offer some fitness benefits. In fact, when hatching takes place at higher strata, the probability that the larvae fall into the water rather than onto the bank (which is challenging in windy conditions) increases with the width of the water. In addition, wider water beds might be correlated with a higher food availability which allows the fast development of larvae which are time-constrained (De Block and Stoks 2004).

There is evidence that body size affects the reproductive behaviour of territorial odonates (Tsubaki and Ono 1987; Serrano-Meneses et al. 2007). Our study investigated the reproductive behaviour and ecology of Chalcolestes viridis at the southern limit of the distribution range and showed no effects of body size. It would be interesting to investigate in further studies whether this pattern holds true for other Lestes in particular and non-territorial species in general. Furthermore, evolutionary studies on a larger scale (including different species) that relates reproductive behaviour, fitness and SSD should be the next step towards understanding the evolution of body size in odonates.

\section{ACKNOWLEDGEMENTS}

We are thankful to two reviewers for their constructive comments and suggestions.

\section{REFERENCES}

Agüero-Pelegrin, María, Manuel Ferreras-Romero, and Philip S. Corbet. 1999. The life cycle of Lestes viridis (Odonata: Lestidae) in twseasonal streams of the Sierra
Morena Mountains (southern Spain). Aquatic insects 21 (3): 187-96.

Amari, Hichem, Rabah Zebsa, Amel Lazli, Soufyane Bensouilah, Mohamed Khalil Mellal, Hayat Mahdjoub, Moussa Houhamdi, and Rassim Khelifa. 2019. Differential elevational cline in the phenology and demography of two temporally isolated populations of a damselfly: not two but one taxa? Ecological Entomology 44 (1): 93-104.

Andersson, Malte B. 1994. Sexual selection: Princeton University Press.

Anholt, Bradley R. 1991. Measuring selection on a population of damselflies with a manipulated phenotype. Evolution 45 (5): 1091-106.

Banks, Michael J., and David J. Thompson. 1987. Lifetime reproductive success of females of the damselfly Coenagrion puella. The Journal of Animal Ecology 56: 815-32.

Blanckenhorn, Wolf U. 2000. The evolution of body size: what keeps organisms small? The quarterly review of biology 75 (4): 385-407. doi: 10.1086/393620.

Bouiedda, Nadia, Hichem Amari, Amina Guebailia, Rabah Zebsa, Nedjwa Boucenna, Sana Hadjadji, Boualem Mayache, Moussa Houhamdi, and Rassim Khelifa. 2018. Reproductive behaviour and body size of Erythromma lindenii (Zygoptera: Coenagrionidae) in Northeast Algeria. Odonatologica 47 (3-4): 267-76.

Corbet, P. S. 1962. A biology of dragonflies. Witherby, London: 247.

-1999. Dragonflies: behaviour and ecology of Odonata. Colchester: Harley Books.

Cordero-Rivera, Adolfo, and Robby Stoks. 2008. Markrecapture studies and demography. In Dragonflies and damselflies: model organisms for ecological and evolutionary research, edited by A. Córdoba-Aguilar, 7-20. Oxford: Oxford University Press.

Cordero, A. 1988. Estudio ecológico de una población de Lestes viridis Vander Linden, 1825 (Zygoptera, Lestidae). Limnética 4: 1-8.

Córdoba-Aguilar, Alex, Juan César Salamanca-Ocaña, and Martha Lopezaraiza. 2003. Female reproductive decisions and parasite burden in a calopterygid damselfly (Insecta: Odonata). Animal Behaviour 66 (1): 81-7.

Cothran, Rickey D., Kristopher Chapman, Andy R. Stiff, and Rick A. Relyea. 2012. "Cryptic" direct benefits of mate choice: choosy females experience reduced predation risk while in precopula. Behavioral Ecology and Sociobiology 66 (6): 905-13.

De Block, Marjan, and Robby Stoks. 2005. Fitness effects from egg to reproduction: bridging the life history transition. Ecology 86 (1): 185-97.

2007. Flight-related body morphology shapes mating success in a damselfly. Animal Behaviour 74 (4): 1093-8.

Dreyer, W. 1978. Etho-ökologische untersuchungen an 
Lestes viridis (Vander Linden) (Zygoptera: Lestidae). Odonatologica 7 (4): 309-22.

Eberhard, William G. 1996. Female control: sexual selection by cryptic female choice. Princeton University Press.

Ferreras-Romero, M. 1988. New data on the ecological tolerance of some rheophilous Odonata in Mediterranean Europe (Sierra Morena, Southern Spain). Odonatologica 17 (2): 121-6.

Fincke, Ola M. 1985. Alternative mate-finding tactics in a non-territorial damselfly (Odonata: Coenagrionidae). Animal Behaviour 33 (4): 1124-37.

Grand, Daniel, and Jean-Pierre Boudot. 2007. Biotope. Les libellules de France. Belgique et Luxembourg.

Khelifa, R., A. Youcefi, A. Kahalerras, A. Al Farhan, K. A. AlRasheid, and B. Samraoui. 2011. L'odonatofaune (Insecta: Odonata) du bassin de la Seybouse en Algérie: intérêt pour la biodiversité du Maghreb. Revue d'écologie 66: 55-66.

Khelifa, R., Hayat Mahdjoub, Mohamed Sahnoun Aouaouche, and Moussa Houhamdi. 2016. Reproductive behaviour of a North African endemic damselfly, Platycnemis subdilatata (Odonata: Platycnemididae) and probable senescence effects. Journal of Odonatology 19: 157-67.

Khelifa, Rassim, Hayat Mahdjoub, Rabah Zebsa, Amin Kahalerras, Amina Guebailia, Hichem Amari, and Moussa Houhamdi. 2013. Aspects of reproductive biology and behaviour of the regional critically endangered Urothemis edwardsii (Odonata: Libellulidae) on Lake Bleu (Algeria). Zoology and Ecology 23 (4): 282-5.

Khelifa, Rassim, and Mohammed Khalil Mellal. 2017. Host-plant-based restoration as a potential tool to improve conservation status of odonate specialists. Insect Conservation and Diversity 10 (2): 151-60.

Khelifa, Rassim, Rabah Zebsa, Hichem Amari, Mohamed Khalil Mellal, Hayat Mahdjoub, and Amin Kahalerras. 2016. A hotspot for threatened Mediterranean odonates in the Seybouse River (Northeast Algeria): are IUCN population sizes drastically underestimated? International Journal of Odonatology 19 (1-2): 1-11.

Khelifa, Rassim, Rabah Zebsa, Hichem Amari, Mohammed Khalil Mellal, Abdelheq Zouaimia, Soufyane Bensouilah, Abdeldjalil Laouar, and Moussa Houhamdi. 2018. The hand of man first then Santa Rosalia's blessing: a critical examination of the supposed criticism by Samraoui 2017. Journal of Insect Conservation 22 (2): 351-61.

Khelifa, Rassim, Rabah Zebsa, Amin Kahalerras, Abdeldjalil Laouar, Hayat Mahdjoub, and Moussa Houhamdi. 2013. Description of the Final Instar Exuvia of Urothemis edwardsii with reference to its Emergence site Selection (Odonata: Libellulidae). Entomologia generalis 34 (4): 303-12.

Khelifa, Rassim, Rabah Zebsa, Abdelkrim Moussaoui, Amin Kahalerras, Soufyane Bensouilah, and Hayat
Mahdjoub. 2013. Niche partitioning in three sympatric congeneric species of dragonfly, Orthetrum chrysostigma, $O$. coerulescens anceps, and $O$. nitidinerve: The importance of microhabitat. Journal of insect science 13 (1): 71.

Koskimäki, J., M. J. Rantala, and J. Suhonen. 2009. Wandering males are smaller than territorial males in the damselfly Calopteryx virgo (L.) (Zygoptera: Calopterygidae). Odonatologica 38 (2): 159-65.

Lutz, Paul E., and Annette R. Pittman. 1968. Oviposition and early developmental stages of Lestes eurinus (Odonata: Lestidae). American Midland Naturalist 80: 43-51.

Matushkina, Natalia A., and Philippe H. Lambret. 2011. Ovipositor morphology and egg laying behaviour in the dragonfly Lestes macrostigma (Zygoptera: Lestidae). International Journal of Odonatology 14 (1): 69-82.

Mellal, M. K., M. Bensouilah, M. Houhamdi, and R. Khelifa. 2018. Reproductive habitat provisioning promotes survival and reproduction of the endangered endemic damselfly Calopteryx exul. Journal of Insect Conservation 22 (3-4): 563-70.

Mellal, Mohammed Khalil, Rabah Zebsa, Mourad Bensouilah, Moussa Houhamdi, and Rassim Khelifa. 2018. Aspects of the emergence ecology of the regionally endangered Coenagrion mercuriale (Odonata: Coenagrionidae) in Northeast Algeria. Zoology and Ecology 28 (3): 224-30.

Miller, Christine W., and Erik I. Svensson. 2014. Sexual selection in complex environments. Annual review of entomology 59: 427-45.

R Development Core Team. 2019. R: A Language and Environment for Statistical Computing. Vienna, Austria: R Foundation for Statistical Computing.

Robert, Paul-A. 1958. Les libellules:(Odonates): Delachaux \& Niestlé.

Rodriguero, M. S., J. C. Vilardi, M. T. Vera, J. P. Cayol, and E. Rial. 2002. Morphometric traits and sexual selection in medfly (Diptera: Tephritidae) under field cage conditions. Florida Entomologist 85 (1): 143-9.

Serrano-Meneses, M. A., A. Córdoba-Aguilar, M. Azpilicueta-Amorín, E. González-Soriano, and Tamas Szekely. 2008. Sexual selection, sexual size dimorphism and Rensch's rule in Odonata. Journal of Evolutionary Biology 21 (5): 1259-73.

Serrano-Meneses, M. A., A. Córdoba-Aguilar, V. Méndez, S. J. Layen, and T. Székely. 2007. Sexual size dimorphism in the American rubyspot: male body size predicts male competition and mating success. Animal Behaviour 73 (6): 987-97.

Śniegula, Szymon, and Frank Johansson. 2010. Photoperiod affects compensating developmental rate across latitudes in the damselfly Lestes sponsa. Ecological Entomology 35 (2): 149-57.

Sokolovska, Natalia, Locke Rowe, and Frank Johansson. 2000. Fitness and body size in mature odonates. Eco- 
logical Entomology 25 (2): 239-48.

Stearns, Stephen C. 1992. The evolution of life histories: Oxford University Press.

Stoks, Robby. 1999. Natural and sexual selection in the damselfly Lestes sponsa. UIA, Departement Biologie. - 2001. Male-biased sex ratios in mature damselfly populations: real or artefact? Ecological Entomology 26 (2): 181-7. doi: doi.org/10.1046/j.1365-2311 .2001.00301.x.

Takami, Y., and T. Sota. 2007. Rapid diversification of male genitalia and mating strategies in Ohomopterus ground beetles. Journal of Evolutionary Biology 20 (4): 1385-95.
Tsubaki, Yoshitaka, and Tomohiro Ono. 1987. Effects of age and body size on the male territorial system of the dragonfly, Nannophya pygmaea Rambur (Odonata: Libellulidae). Animal Behaviour 35 (2): 518-25.

Uhía, Edith, and Adolfo Cordero Rivera. 2005. Male damselflies detect female mating status: importance for postcopulatory sexual selection. Animal Behaviour 69 (4): 797-804.

Zebsa, Rabah, Rassim Khelifa, and Amin Kahalerras. 2014. Emergence pattern, microhabitat choice, and population structure of the Maghribian endemic Gomphus lucasii Selys, 1849 (Odonata: Gomphidae) in northeastern Algeria. Aquatic insects 36 (3-4): 245-55. 